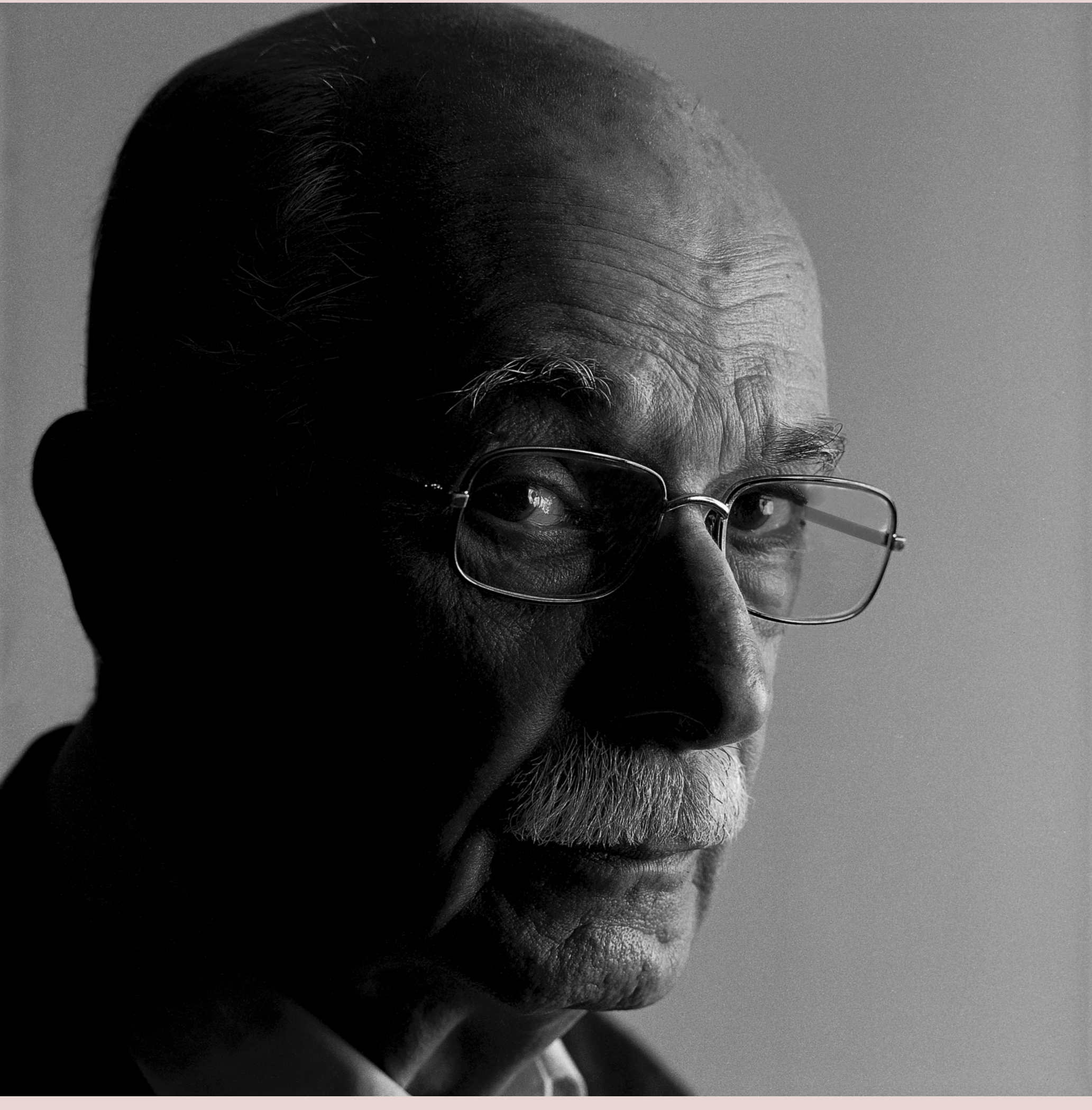

ANTONIO CANDIDO, 1998. FOTOGRAFIA DE JUAN ESTEVES 


\section{CANDIDO E DÉCIO: UMA AMIZADE DE SESSENTA ANOS ${ }^{1}$}

João Roberto Faria

Para homenagear Décio de Almeida Prado, que faria cem anos no próximo dia 14 de agosto, pensei em escrever um artigo sobre o seu legado, abordando as contribuições que deixou como crítico teatral, historiador do nosso teatro, editor do Suplemento Literário d'O Estado de S. Paulo e professor da Universidade de São Paulo, entre outras atividades.

A morte recente do nosso maior crítico literário, Antonio Candido, em maio passado, me fez mudar de ideia quanto à natureza do texto que em princípio escreveria. $\mathrm{O}$ que farei nas linhas seguintes é lembrar e celebrar a amizade que os uniu por cerca de seis décadas, porque ao final transcreverei um texto inédito de Candido a respeito de Décio, que recebi das mãos do autor há dezessete anos. Mais à frente explico em que circunstâncias.

Os dois se tornaram amigos no final dos anos 1930, quando frequentaram as aulas da Faculdade de Filosofia, Ciências e Letras da Universidade de São Paulo. No início da década de 1940, eles fizeram parte de uma turma de rapazes e moças egressos ou ainda cursando a Faculdade de Filosofia. Com interesses comuns, trocavam ideias sobre literatura, iam ao teatro e ao cinema, aos concertos, encontravam-se nas confeitarias, conversavam muito, complementando a formação intelectual uns dos outros. Por sugestão de um amigo mais velho, Alfredo Mesquita, esse grupo criou a revista Clima, que teve dezesseis números entre 1941 e 1944. Era o espírito universitário que chegava à atividade crítica, sob a liderança de uma geração brilhante, formada por Candido, Décio, Paulo Emílio Salles Gomes, Gilda de Mello e Souza, Lourival Gomes Machado e Ruy Coelho, entre outros. Todos treinaram a mão nas páginas de Clima, e destacaram-se em seus

1 Texto originalmente publicado no "Caderno 2" d'O Estado de S. Paulo, em 12 de agosto de 2017, pp. 6-7. 
campos de atuação nas décadas seguintes, tanto na imprensa quanto na universidade.

Candido tornou-se crítico literário da Folha da Manhã em 1943, e entre 1945 e 1947 escreveu para o Diário de S. Paulo. A partir de 1947, colaborou em vários jornais e revistas, ao mesmo tempo que se dedicava à carreira de professor universitário, recém-iniciada. Décio, por sua vez, foi crítico teatral d'O Estado de S. Paulo entre 1946 e 1968, ingressando na Universidade de São Paulo como professor em 1964.

A amizade entre os dois teve alguns lances curiosos. Em três ocasiões, Décio não pôde escrever sua coluna de crítica teatral, "Palcos e Circos", e pediu a Candido que o fizesse em seu lugar. Na época, os textos não eram assinados e ninguém ficou sabendo, tamanha a competência com que o trabalho foi feito. Brincalhão, Décio costumava dizer que eram suas melhores críticas. Uma delas, datada de 30 de outubro de 1948, versou sobre a peça The Narrowest Street, de um jovem americano que se tornaria um dos maiores historiadores do Brasil, Richard Morse.

Candido apoiou bastante o trabalho de modernização teatral dos grupos amadores paulistas, na década de 1940, tendo sido "Ponto" do Grupo de Teatro Experimental (GTE), dirigido por Alfredo Mesquita, e traduzindo O baile dos ladrões, de Anouilh, para o Grupo Universitário de Teatro (GUT), liderado por Décio. Em 18 de janeiro de 1945, publicou o artigo "Renovação teatral”, n'O Estado de S. Paulo, no qual mostrou estar a par dos esforços empreendidos pelos amadores, que iniciaram no Brasil "o movimento em prol da elevação do nível artístico”. Entre os grupos citados, ganharam destaque Os Comediantes, do Rio de Janeiro, o GTE e o GUT.

Ao final da Segunda Guerra Mundial, com a queda de Getúlio e o clima de liberdade política reinstaurado, Candido e Décio filiaram-se à Esquerda Democrática, que em 1947 se transformou no Partido Socialista Brasileiro. "Igualdade econômica e liberdade política" era a divisa dos militantes, que não aceitavam a orientação stalinista do Partido Comunista Brasileiro. Os dois jovens intelectuais foram candidatos a deputado estadual, uma curiosidade de suas biografias, pois não repetiram a experiência. Juntos, pregaram cartazes pelas ruas e pediram votos no dia da eleição, mas não se elegeram.

A amizade e a confiança que tinham um no outro continuaram firmes. Em 1955, Candido foi convidado por Júlio Mesquita Neto para organizar e dirigir o Suplemento Literário d'O Estado de S. Paulo. A primeira tarefa foi aceita; a segunda, não. Quando a direção do jornal lhe pediu a indicação de um diretor, não teve dúvidas: o melhor nome era o de Décio. Ambos então discutiram o projeto, fizeram a lista dos primeiros colaboradores e desenvolveram juntos uma série de ideias para implementar o Suplemento, que Décio dirigiu entre 1956 e 1967. Para muitos intelectuais, foi o ponto alto do jornalismo 
cultural em São Paulo, que nunca mais conseguiu repetir o elevado patamar atingido.

Em 1964, Candido fez um segundo convite a Décio: tornar-se professor do curso de Letras da Universidade de São Paulo, na área de Teoria da Literatura. O mesmo convite foi feito a Paulo Emílio Salles Gomes. A ideia era reunir num mesmo departamento os três especialistas em literatura, teatro e cinema, respectivamente, que não por acaso começaram juntos na revista Clima e continuaram juntos no Suplemento Literário. Paulo Emílio aceitou, mas Décio acabou indo para a área de Literatura Brasileira, na qual criou novas disciplinas e se dedicou ao estudo da nossa dramaturgia e da história do teatro brasileiro, com especial atenção à trajetória artística do grande ator romântico João Caetano dos Santos e aos autores teatrais do século XIX.

Candido e Décio deram muitas demonstrações públicas do afeto e admiração que sentiam um pelo outro, em várias entrevistas e em homenagens que receberam por suas trajetórias como críticos e professores. Em 1990, a III Jornada de Ciências Sociais da Unesp, realizada em Marília, reuniu um expressivo grupo de intelectuais para homenagear Candido. Entre eles, estava Décio, que fez um depoimento bastante divertido, intitulado "Antonio Candido e a pena da galhofa". No texto, lembrava o espírito lúdico do amigo, que sabia imitar pessoas, estilos e sotaques, "o farsista capaz eventualmente de sair pelas ruas de Portugal torcendo o bigode e ostentando uma impecável prosódia portuguesa". Lembrava também outra brincadeira dos tempos de Clima - a teoria filosófica do "Grouxismo", baseada nos filmes de Grouxo Marx - e o gosto que ambos tinham pela ópera. Neste caso, Candido mandou de presente a Décio uma biografia de Rodolfo Valentino, acompanhada de uma carta em italiano, datada de 18 de julho de 1979 e supostamente escrita pelo famoso ator - ídolo dos dois quando meninos - ao "chiarissimo Professore d'Almeyda”. A carta é uma montagem construída com frases de óperas como Cavalleria Rusticana, Turandot, Rigolleto, La Favorita, entre outras. Confira o leitor no livro Dentro do texto, dentro da vida: ensaios sobre Antonio Candido, organizado por Maria Angela D'Incao e Eloísa Faria Scarabôtolo (São Paulo: Companhia das Letras, 1992).

Em 18 de novembro de 1994, a União Brasileira de Escritores, com o apoio da Associação Paulista de Autores Teatrais (Apart) e do Sindicato dos Artistas e Técnicos em Espetáculos de Diversões do Estado de São Paulo (Sated/sP), fez uma sessão de homenagem a Décio, na Biblioteca Mário de Andrade. Candido foi um dos participantes e em sua fala ressaltou o papel decisivo do amigo para "a continuidade e a regularidade de Clima”, bem como a "notável atuação como diretor do Suplemento Literário d'O Estado de S. Paulo", acrescentando: 
Pode-se dizer que ninguém era mais indicado do que ele para essa tarefa difícil e trabalhosa. Isto, em virtude do seu tipo de personalidade, equilibrada com uma harmonia rara. Nela se fundem a maestria da inteligência e o alto teor humano, de maneira a definir uma atitude permanente de compreensão e justiça. Por isso, pôde fazer do Suplemento, durante tantos anos, um lugar de encontro de tendências diversificadas e válidas da literatura brasileira daquele momento, combinando modernidade e tradição, como é típico do meio cultural de São Paulo que ele encarna tão bem. ${ }^{2}$

Posso dar um testemunho pessoal da estima e da admiração de Candido por Décio. Em abril ou maio de 1996, ele convidou a mim, Vilma Arêas e Flávio Aguiar para uma conversa em sua casa. Disse-nos então que devíamos organizar um livro para homenagear Décio, que em agosto do ano seguinte faria oitenta anos. A seu ver, era preciso dar mais visibilidade e proporcionar maior reconhecimento à obra e à trajetória intelectual do velho amigo. Chamou-nos porque éramos próximos de Décio: Flávio Aguiar dividira com ele as aulas sobre teatro brasileiro no curso de Letras; Vilma Arêas tinha sido sua orientanda na pós-graduação; eu não só fora orientado por ele na pós-graduação, como fiquei em seu lugar como professor, logo depois que se aposentou, em 1982. Para nos orientar, Candido traçou um plano para o livro, que seguimos à risca, organizando-o em três partes: a primeira, com breves depoimentos, principalmente de artistas de teatro e colaboradores do Suplemento Literário; a segunda, com artigos sobre Décio e sua obra; a terceira, com artigos de temas livres. No dia 14 de agosto de 1997, com a presença do homenageado, fizemos o lançamento de Décio de Almeida Prado: um homem de teatro, editado pela Edusp/Fapesp, no Tusp da rua Maria Antônia. Foi uma bela festa, com a presença de muitos de seus amigos, antigos alunos e admiradores.

Em 1998, foi a vez de Candido fazer oitenta anos. Uma comissão formada por professores e intelectuais das três universidades estaduais paulistas, do Instituto de Estudos Avançados da usP, do Núcleo de Literatura e Crítica Literária sediado na Casa Mário de Andrade, da Associação dos Docentes da usp e da Fundação Perseu Abramo organizou no mês de agosto o evento "Antonio Candido: pensamento e militância". Entre os palestrantes, Décio relembrou a juventude de ambos, a formação do crítico literário, que desde os tempos da revista Clima "tinha o relativo domínio de sua matéria" e que já no primeiro artigo procurava uma base teórica: "Já o intrigava a relação entre a obra literária, de natureza individual, devendo ser

2 LUCAs, Fabio; União Brasileira de Escritores.. 


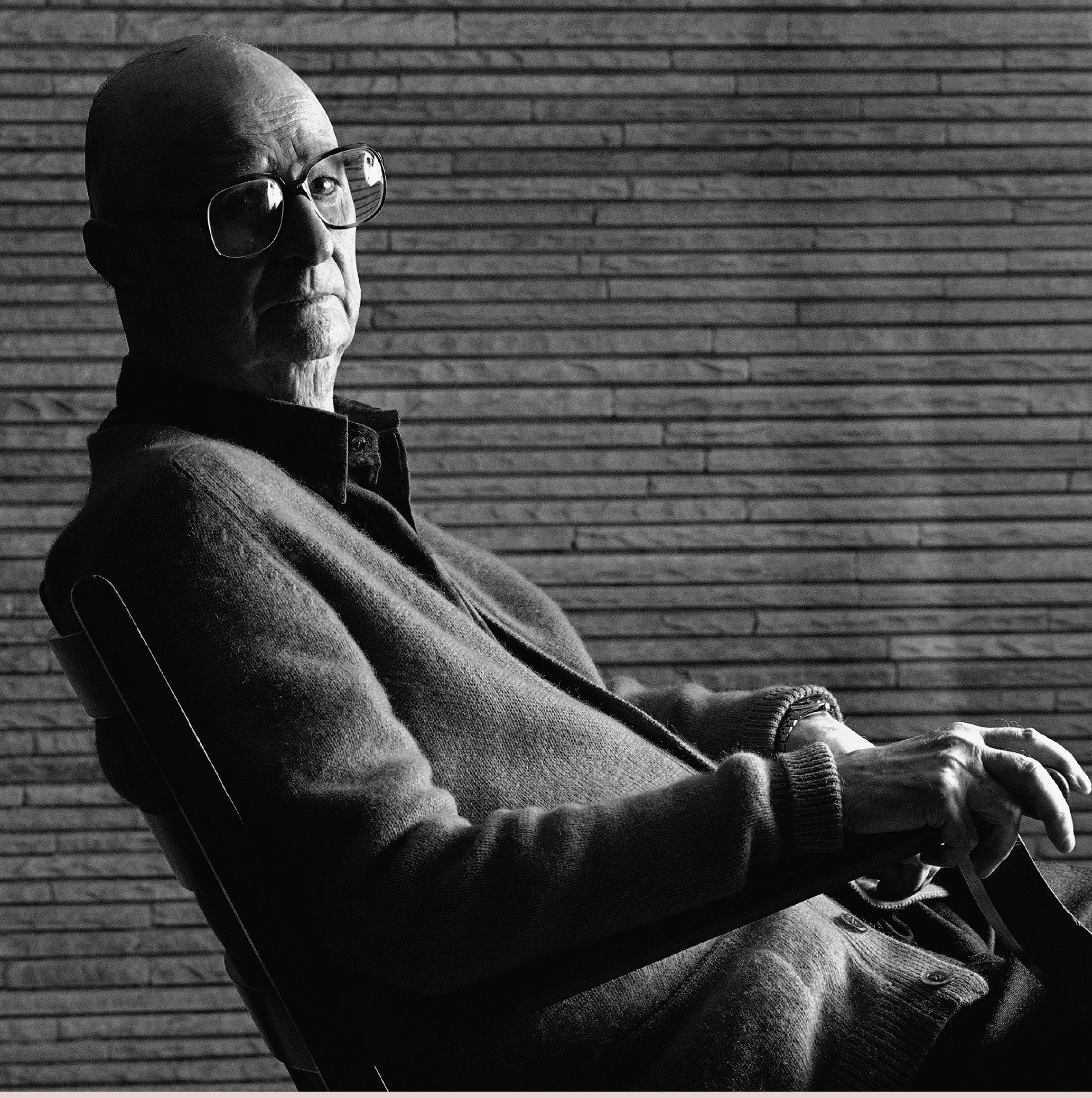

DÉCIO DE ALMEIDA PRADO, 1999. FOTOGRAFIA DE JUAN ESTEVES 
lida por sua singularidade, e o quadro social em que se inscreve, relação esquiva, difícil de detectar, que seria amplamente discutida e elucidada na Formação da literatura brasileira".

Décio não teve outra oportunidade para falar em público ou escrever sobre Candido, pois faleceu em fevereiro de 2000. Eu estava nos Estados Unidos como professor visitante na Universidade do Wisconsin, em Madison, e não pude me despedir do mestre e amigo de tantos anos. Ao voltar para o Brasil, em junho de 2000, fiz uma visita a Candido e conversamos muito sobre Décio. Foi então que ele me presenteou com três páginas datilografadas, encimadas pela seguinte explicação: "O que segue não foi escrito sob a impressão da morte de Décio de Almeida Prado. É transcrito do meu caderno de notas, com data de 24 de maio de 1996".

Pela data, percebo que as páginas, com o título "Apogeu", foram escritas por Candido na mesma época em que fez o plano para o livro em homenagem a Décio. Guardo-as comigo há dezessete anos, sem tê-las divulgado antes, porque me pareceu que essa era a vontade de seu autor. Se o faço agora, é porque entendo que são páginas importantes para todos que se interessam pela vida cultural brasileira. Seria egoísmo de minha parte não compartilhá-las com o maior número possível de pessoas. Além disso, são lindamente escritas e jogam mais luz sobre o que procurei deixar claro desde o início: a forte amizade que os uniu ao longo de suas vidas, o afeto e a admiração que tinham um pelo outro. Por fim, não vejo melhor maneira de lembrar o centenário de Décio. O elogio do amigo, que transcrevo abaixo, é desses textos definitivos, que iluminam igualmente as qualidades intelectuais e humanas de quem o escreveu.

3 Aguiar, Flávio (org.). Antonio Candido: pensamento e militância. São Paulo: Humanitas; Fundação Perseu Abramo, 1999. 


\section{APOGEU}

Antonio Candido,

24 de maio de 1996

O artigo do Décio "Saudade de Lévi Strauss" revela bem quem ele é. Revela as suas grandes qualidades, tão equilibradas e discretas que parecem menos do que na verdade são. Em pouco espaço, com ar de quem conversa, misturando o subjetivo da evocação com a descrição objetiva do real, ele consegue ressuscitar o que era a cidade de São Paulo nos anos 30: qual a sua fisionomia, qual a atmosfera intelectual, qual o significado da Faculdade como nova forma de proposta no campo da cultura. Mais ainda: consegue sugerir a passagem do tempo, mostrando, como quem não quer, o estado atual desses aspectos, chegando a um resultado cheio de informação e significado, sempre por meio de alusões mínimas, associações aparentemente espontâneas e um tom de tal maneira despretensioso, que o leitor parece ter experimentado ele próprio o que desconhecia ou não tinha sabido interpretar. E assim percebemos que o artigo aparentemente casual é fruto de um amadurecimento e um discernimento acessíveis a bem poucos, pois pressupõe uma qualidade rara nos intelectuais: mostrar força e profundidade por meio da simplicidade mais completa.

Outro dia, não me lembro quem me disse que só agora o Décio está sendo descoberto e avaliado da maneira que lhe é devida, porque estão percebendo a sua verdadeira eminência. Esse reconhecimento vagaroso acontece com os que não batem caixa e não se envolvem nas atividades que costumam projetar as pessoas no espaço público. $E$ ainda bem que o reconhecimento geral chegou a tempo de dar o destaque devido a um dos maiores intelectuais do Brasil, um homem que teve a sabedoria de só 
fazer aquilo de que era capaz, recusando qualquer trilho onde não sentisse chão adequado à sua caminhada. Nisso a sorte o ajudou, porque nunca teve necessidade de renunciar aos pendores e trabalhar por obrigação no que não era o seu interesse estrito.

A força singular do Décio se manifesta antes de mais nada na escrita, que é perfeita, sem truques nem ênfase, de uma urbanidade bem adequada à singeleza, mas sem a parcimônia excessiva, que freia a manifestação da personalidade e esconde o modo de ser. Isso, porque ele é sempre rigorosamente sincero e, sem se exibir um milímetro, só escreve o que pensa e como pensa, sem buscar "efeitos" que impressionem. Nenhum outro estilo é tão alheio à simulação, à argúcia construída, ao dó de peito. Firme no seu tom moderado, ele o transforma em instrumento de uma visão reta e autêntica. A sua limpidez traduz a retidão e a sua retidão como escritor nada mais é do que o desdobramento da sua perfeita integridade de homem que não sabe mentir.

No começo dos anos 40, as moças da "turma" (Gilda, Dorothy, Ruth, Sarah, lolanda, Helena) fizeram uma espécie de consulta entre elas para saber qual de nós, rapazes, era 100\%. O Décio foi o escolhido por unanimidade e elas Ihe deram de presente uma edição de Rabelais em formato grande. Iniciativa discreta, da qual a Sarah me informou na ocasião.

Essa decisão foi perfeita. De todos nós o Décio foi sempre o mais completo sob o aspecto moral, intelectual e de convívio. Bem educado, alegre, sereno, justo, brioso, de rara saúde mental, solidário, capaz de dedicação, não tem os nossos defeitos e já manifestava, mal saído da adolescência, a harmonia de qualidades que alicerçam a sua inteligência penetrante, capaz de extrair o máximo de uma tendência comum a todos nós de Clima: o apego ao concreto, a relativa incapacidade de abstração, o gosto pelas coisas do mundo tanto quanto pelas da mente. Coroando, o raro dom de explorar ao máximo as próprias capacidades, mas sem atravessar os limites das possibilidades, evitando por uma espécie de instinto seguro (que é sabedoria) dar passo maior que a perna. 
Esse equilíbrio talvez explique também a constância nos gostos, na amizade, bem como a fidelidade a certas e poucas tarefas. Ele não se multiplica. Ao contrário, concentra-se e se apega, porque tem necessidade de cumprir o que prometeu, sem abandonar o campo. No caso de Clima, tornou-se logo o realizador. O Alfredo se afastou depois do primeiro número e o Lourival não assumiu as tarefas de direção depois do segundo. Ele e Ruth chamaram a si a responsabilidade, fizeram de sua casa a verdadeira redação e centralizaram a produção da revista, ajudados sobretudo por Gilda, pelo Ruy e por mim. Sem o casal, Clima teria provavelmente acabado no terceiro número.

Restrito ao teatro, ensinando no secundário e, depois de ir já quarentão para a Universidade, ficando fora de seus problemas e tensões, ele atuou em âmbito mais restrito e não teve desde logo a fama a que fazia jus, apesar de ter ficado conhecido e admirado como excelente crítico teatral, e apesar de ter adquirido muito nome a partir do decênio de 1950 como perfeito diretor do "Suplemento" do Estado de S. Paulo. Alma de Clima, alma do "Suplemento", ele serviu sem exigir e se contentou em cumprir as tarefas. Enquanto isso, ia acumulando escritos de alta qualidade, inclusive com base na pesquisa, como demonstram as teses sobre João Caetano. A de livre-docência foi um dos elementos que, com a aula e a prova escrita, fizeram de seu concurso um dos mais belos que já vi. E agora, esse longo, discreto e tranquilo esforço recebeu o coroamento, já que na fase final da vida está sendo reconhecido em escala compatível com o seu valor. 